\title{
Morphometric Study of Ulnar Styloid Process and its Clinical Implication
}

\author{
Authors \\ Dr Kewal Kishore Thakur, Dr Rekha, Dr Simriti*, Dr Bias Dev \\ Department of Anatomy, Government Medical College Jammu, Jammu and Kashmir \\ *Corresponding Author \\ Dr Simriti \\ B 2 Medical Enclave, GMC Jammu, 180001, India \\ Mob:9419787722. Email: Simritibias20@gmail.com
}

\begin{abstract}
The lower end of ulna contributes to the formation of joint through intervening triangular disc and it is of great anatomical and physiological significance for normal hand functioning. Lower end of ulna consist of head, fovea and styloid process. The study of styloid process is of great importance to orthopaedic surgeons for differential diagnosis of wrist pain. There is correlation between the morphometry of ulnar styloid process of ulna and painfull conditions of the wrist such as ulnar impaction syndrome, ulnar styloid triquetral impaction syndrome. It is therefore important to distinguish between variation of ulnar styloid process and disorders of distal radioulnar joint for appropriate surgical treatment by various orthopaedic surgeons. The present study was conducted with the objective to correlate the morphometry of styloid process of right and left side of ulna so that the pain and fractures of styloid process can be easily diagnosed and managed appropriately.

Keywords: Styloid process, Distal radioulnar joint.
\end{abstract}

\section{Introduction}

Wrist joint is formed by various bones and ligaments, having many articulations so forming a complex joint for performing various diverse functions of hand. Lower end of radius, ulna and carpel bones contributes to the wrist joint. The lower end of ulna contributes to the formation of joint through intervening triangular disc and it is of great anatomical and physiological significance for normal hand functioning. In recent time there has been considerable interest in managing and fixing the styloid process by orthopaedic surgeons.

The lower end of ulna consists of head, ulnar styloid process and fovea Styloid process is derived from Greek word 'stylos' meaning pillar refers to the slender pointed process, serving as point of attachment of muscles or ligaments. The styloid process of ulna is found at distal end of the forearm and projects from medial and dorsal part of ulna bone. It lies about $1 \mathrm{~cm}$ proximal to plane of styloid process of radius and descends little lower than head ${ }^{1}$. The complex anatomy of this region with small size of the structures present a diagnoistic challenge for hand surgeons and radiologist ${ }^{2}$. Any alteration in morphology and morphometry of styloid process can produce ulnar styloid triquetral impaction syndrome ${ }^{3}$. Excessively long ulnar styloid process has important implication for kinematics of the 
lunatotriquetral interval ${ }^{4}$. Rounded end of styloid process affords attachment to ulnar collateral ligament of the carpus and carpal instability may occur in facture of ulnar styloid process. These fractures are treated conservatively with splint bandage for two to three weeks if carpal joint is considered stable. If it is associated with antebrachiocarpal instability, distal segment is reattached with tension band fixation.

Detailed anatomical knowledge of distal end of ulna plays a pivotal role in understanding post injury instability and painful conditions at distal radioulnar joint, which can be due to avulsion of ulnar styloid process or styloid triquetral impaction syndrome ${ }^{5}$. The importance of the ulnar side of the wrist is being considered more carefully as more and more surgeons realize that in order to improve the outcome after distal forearm fractures, the ulnar side needs more attention $^{6}$.

The wrist with elongated ulnar styloid process is prone to develop ulnar impaction syndrome ${ }^{7}$. The ulnar impaction syndrome can be defined as the impaction of ulnar head against the triangular fibro cartilage complex and ulnar carpus resulting in progressive degeneration of these structures ${ }^{8}$. While shortening of distal ulna that impinges on distal radius causes ulnar impingement syndrome. It causes painful disabling pseudoarthrosis ${ }^{9}$. When carpels impact with ulnar styloid process,partial recesetion of styloid process provides successful treatment ${ }^{10}$. It is therefore important to distinguish between ulnar impaction, ulnar impingement and disorders of distal radioulnar joint for appropriate surgical treatment.

Ulnar styloid fracture is a common occurrence especially when a person falls on an outstretched hand. It often causes pain, swelling and difficulty in movement. Proper diagnosis and treatment is necessary to preserve the functioning of wrist joint. Ulnar styloid fractures may be predocitive factor for worst functional outcome for distal radial fractures ${ }^{11}$. It is important to know the causes, symptoms, treatment and rehabilitation of ulnar styloid fracture.
Sometimes the styloid process of ulna is placed posterolaterally instead of normal posteromedial position. Here the subject may complain of decreased ulnar deviation of wrist. This is a morphological variation of position of ulnar styloid process and should be suspected in case of ulnar wrist pain ${ }^{7}$. Detailed morphometric study of styloid process of ulna provides an anatomical data base of distal end of ulna which helps in early management of wrist pain, impingement syndrome and ulnar styloid triqueteral impaction syndrome.

\section{Aims and Objectives}

The knowledge of morphology and morphometry of styloid process plays an important role in various surgical and diagnostic procedures. The present study was conducted with the objective to correlate the morphometry of styloid process of right and left side of ulna so that the pain and fractures of styloid process can be easily diagnosed and managed appropriately.

\section{Material and Methods}

The material for the present study comprised of 70 ulna bones of unknown age and sex. The bones selected were 35 of right side and 35 of left side and they were labeled as suffix ' $r$ ' for right side and suffix ' 1 ' for left side.

The instruments used were vernier caliper to measure diameter and length with accuracy. Cotton thread for measuring circumference of styloid process. All measurements were taken in millimeters ( $\mathrm{mm})$.

Parameters taken were

1. Position of Styloid Process: It was noted down whether posteriormedial or any other type.

2. Length of styloid process: Measured as the distance from the point where it springs out from head upto the tip of styloid process.

3. Width of styloid process: Measured as two farthest points placed horizontally at the base of styloid process. 
4. Posterior groove between the head and the styloid process: It was noted down whether distinct/not distinct.

\section{Observations and Results}

All measurements were taken on anatomical sound basis and special attention were given to the presence of zero error in the instruments used. Various statistical results calculated were mean with standard deviation (mean \pm SD) and standard error of mean (SEM).

Length Width and Circumference are shown in tabulated form.

\section{Length of styloid process}

Table 1: Mean length of styloid process of right, left and total ulna bones

\begin{tabular}{|l|c|c|c|c|}
\hline \multirow{2}{*}{ Ulna bones } & \multirow{2}{*}{ No. } & \multicolumn{3}{|c|}{ Length of Styloid Process } \\
\cline { 3 - 5 } & 35 & Mean $\pm \mathrm{SD}(\mathrm{mm})$ & SEm & Range $(\mathrm{mm})$ \\
\hline Right & $35.61 \pm 0.57$ & 0.09 & $4.8-7.2$ \\
\hline Left & 35 & $5.43 \pm 0.60$ & 0.10 & $4.2-7.1$ \\
\hline Total & 70 & $5.52 \pm 0.59$ & 0.09 & $4.2-7.2$ \\
\hline
\end{tabular}

\section{Width of Styloid process}

Table 2. Mean Width of Styloid process of right, left and total ulna bones

\begin{tabular}{|c|c|c|c|c|}
\hline \multirow{2}{*}{ Ulna Bones } & \multirow{2}{*}{ No. } & \multicolumn{3}{|c|}{ Width of Styloid Process } \\
\cline { 3 - 5 } & 35 & Mean \pm SD $(\mathrm{mm})$ & SEm & Range $(\mathrm{mm})$ \\
\hline Right & 35 & $5.55 \pm 0.64$ & 0.10 & $4.1-6.8$ \\
\hline Left & 70 & $5.46 \pm 0.53$ & 0.08 & $4.1-6.4$ \\
\hline Total & & 0.09 & $4.1-6.8$ \\
\hline
\end{tabular}

\section{Mean circumference of Styloid process}

Table 3 Mean circumference of Styloid process of right, left and total ulna bones

\begin{tabular}{|c|c|c|c|c|}
\hline \multirow{2}{*}{ Ulna Bones } & \multirow{2}{*}{ No. } & \multicolumn{3}{|c|}{ circumference of Styloid Process } \\
\cline { 3 - 5 } & 35 & Mean $\pm \mathrm{SD}(\mathrm{mm})$ & SEm & Range $(\mathrm{mm})$ \\
\hline Right & $35.14 \pm 2.20$ & 0.37 & $15-24$ \\
\hline Left & 35 & $18.46 \pm 1.83$ & 0.30 & $14.5-23.2$ \\
\hline Total & 70 & $18.80 \pm 2.01$ & 0.34 & $14.5-24$ \\
\hline
\end{tabular}

Posterior groove between head and styloid process: In the present study, it was found to be distinct in $61(87.14 \%)$ bones, while in 09 $(12.86 \%)$ bones the groove was indistinct.

\section{Discussion}

In all the 70 bones, the position of styloid process was found to be posteromedial. The mean length of styloid process was found to be 5.60 (SD \pm $0.54) \mathrm{mm}$ with a range of 4.8 to $7.0 \mathrm{~mm}$ and 5.43 $(\mathrm{SD} \pm 0.60) \mathrm{mm}$ with a range of 4.2 to $7.1 \mathrm{~mm}$ on the right and left side ulna bones respectively. Garcia has developed a method of assessing the relative size of styloid process ${ }^{12}$.

Sharma observed that the mean length of the styloid process was $5.2 \pm 0.82 \mathrm{~mm}$ and $5.0 \pm$ $0.67 \mathrm{~mm}$ on the right and left side ulna bones respectively ${ }^{5}$. Hence the findings of the present study are in accordance with those of Sharma ${ }^{5}$.

If the length of ulnar styloid process was $>6 \mathrm{~mm}$ it was considered a criterion for long ulnar styloid process. In the present study, total of 12 (6right and 6 left) ulna bones were found to be having long ulnar styloid process. The importance of length of ulnar styloid process as a causative factor in ulnar styloid triquetral impaction (USTI) producing ulnar sided wrist pain ${ }^{3,4}$.

The mean width of styloid process in the present study observed was 5.55 ( $\mathrm{SD} \pm 0.64) \mathrm{mm}$ and 5.37 $(\mathrm{SD} \pm 0.53) \mathrm{mm}$ for right and left ulna bones respectively. The mean was also found to be slightly right side on the right side. Range was also found to be higher on the right side (4.1 to 6.8 $\mathrm{mm}$ ) as compared to left side (4.1 to $6.4 \mathrm{~mm}$ ). 
Mean circumference of styloid process was found to be $19.14(\mathrm{SD} \pm 2.20) \mathrm{mm}$ and $18.46(\mathrm{SD} \pm 1.83)$ $\mathrm{mm}$ for right and left side of ulna bones respectively. Range on the right side observed was 18 to $24 \mathrm{~mm}$ and 14.5 to 24 on the left side.

Detailed anatomical knowledge of the styloid process of ulna playa $=\mathrm{s}$ an important role in understanding the post injury instability and painful conditions at the distal radioulnar joint (DRUJ), which can be either due to avulsion of ulnar styloid process or ulnar styloid triquetral impaction syndrome ${ }^{5}$.

Posterior groove between head and styloid process was found to be distinct in $62(89 \%)$ ulna bones and indistinct in 8 (11\%; 3 right and 5 left) ulna bones. While studying the posterior groove between head and styloid process on 100 bones demonstrated that 90 bones were having distinct groove, whereas in 10 bones the groove indistinct ${ }^{5}$.

Thus our finding are in consistent with the finding of Sharma.

This groove forms the fibro-osseous tunnel for the passage of tendon of extensor carpi ulnaris which helps in unrestricted rotation of radius on ulna at distal radioulnar joint.

Mean length, width and circumference of the styloid process were observed on both sides values were found to be slightly higher on the right sided ulna bones.

The results thus calculated provide important information about the right and left asymmetry of human ulnar styloid process to Anatomist, Fronseic experts and Oethopaedic Surgeons.

\section{Conclusion}

In the present study morphometric parameters of ulnar styloid process were measured and compared on both sides and values were found to be slightly higher on right sided ulna bone.

Thus the results calculated, provide important information about right and left asymmetry of lowerend of ulna for amatomist and orthopaedic surgeons. This knowledge will help orthopaedicans in selecting various treatment modalities in fractures and dislocations pertaining to lower end and surgical procedure.

\section{Bibliography}

1. Standring S. Gray's Anatomy. The Anatomical Basis of Clinical Practice, $40^{\text {th }}$ edition. Churchill Livingstone (Elsevier) 2005; pp. 843-844.

2. Vezeridis PS, Yoshioka H, Han R and Blazar P. Ulnar-sided wrist pain. Part 1: anatomy and physical examination. Skeletal Radiol 2010; 39(8): 733-745.

3. Giachino AA,McIntyre AI, Guy KJ and Conway AF. Ulnar Styloid triquetral impaction. Hand Surg2007;12 (2): 123134.

4. Topper SM, Wood MB and Ruby LK. Ulanr styloid impaction Syndrome. J Hand Surg Am 1997; 22(4): 699-704.

5. Sharma A, Kumar A and Singh P. Anatomical study of the distal end of ulnae: a clinical consideration for the management of distal radioulnar joint injuries. Singapore Med J 2011; 52 (9) 673-676.

6. A.J. Logan, T.R. Lindau. The management of distal ulnar fractures in adults: a review of the literature and recommendations for treatment. Strat Traum Limb Recon ( 2008) 3:49-56.

7. Koka AH, Sajad $M$ and Ahmad K. Posterolateral ulnar styloid process - a morphological variation. Internet J Orthopedic Surg 2009; 11 (2): 10.5580/175a.

8. Friedman SL and Palmer AK. The ulnar impaction syndrome. Hand Clin1991;7 (2): 295-310.

9. Bell MJ,Hill RJ, and McMurtry Ry. Ulnar impengiment syndrome. Br J Bone Joint Surg 1985; 67: 126-129.

10. Tomaino MM, Gainer M and Towers JD. Carpal impaction with the ulnar styloid process: treatment with partial styloid resection. J Hand Surg $\mathrm{Br} 2001 ; 26(3)$ : 252-255. 
11. J C Belloti, VY Moraes, MB Albers, F Faloppa, JBS Dos Santos. Doer an ulnar styloid fracture interfere with the results of adistal radius fracture? Journal of Orthopaedic Science 15 (2), 216-222.

12. Garcias- Elias M. Dorsal Fractures of The Triquetrium, avlusion Or Compression Fractures. J Hand Surg Am.1987 Mar;12(2):266-8. 